\title{
Power-controlled temperature guided retinal laser therapy
}

\author{
Alexander Baade \\ Claus von der Burchard \\ Meike Lawin \\ Stefan Koinzer \\ Benedikt Schmarbeck \\ Kerstin Schlott \\ Yoko Miura \\ Johann Roider \\ Reginald Birngruber \\ Ralf Brinkmann
}




\title{
Power-controlled temperature guided retinal laser therapy
}

\author{
Alexander Baade, ${ }^{\mathrm{a}, \star}$ Claus von der Burchard, ${ }^{\mathrm{b}}$ Meike Lawin, ${ }^{\mathrm{a}}$ Stefan Koinzer, ${ }^{\mathrm{b}}$ Benedikt Schmarbeck, ${ }^{\mathrm{a}}$ \\ Kerstin Schlott, ${ }^{\mathrm{a}}$ Yoko Miura, ${ }^{\mathrm{c}}$ Johann Roider, ${ }^{\mathrm{b}}$ Reginald Birngruber, ${ }^{\mathrm{a}, \mathrm{c}}$ and Ralf Brinkmann ${ }^{\mathrm{a}, \mathrm{c}}$ \\ ${ }^{a}$ Medizinisches Laserzentrum Lübeck $\mathrm{GmbH}$, Lübeck, Germany \\ 'University Medical Center of Schleswig-Holstein, Department of Ophthalmology, Kiel, Germany \\ 'University of Lübeck, Institute of Biomedical Optics, Lübeck, Germany
}

\begin{abstract}
Laser photocoagulation has been a treatment method for retinal diseases for decades. Recently, studies have demonstrated therapeutic benefits for subvisible effects. A treatment mode based on an automatic feedback algorithm to reliably generate subvisible and visible irradiations within a constant irradiation time is introduced. The method uses a site-individual adaptation of the laser power by monitoring the retinal temperature rise during the treatment using optoacoustics. This provides feedback to adjust the therapy laser power during the irradiation. The technique was demonstrated on rabbits in vivo using a 532-nm continuous wave Nd:YAG laser. The temperature measurement was performed with 523-nm Q-switched Nd:YLF laser pulses with $75-\mathrm{ns}$ pulse duration at $1-\mathrm{kHz}$ repetition rate. The beam diameter on the fundus was $200 \mu \mathrm{m}$ for both lasers, respectively. The aim temperatures ranged from $50^{\circ} \mathrm{C}$ to $75^{\circ} \mathrm{C}$ in 11 eyes of 7 rabbits. The results showed ophthalmoscopically invisible effects below $55^{\circ} \mathrm{C}$ with therapy laser powers over a wide range. The standard deviation for the measured temperatures ranged from $2.1^{\circ} \mathrm{C}$ for an aim temperature of $50^{\circ} \mathrm{C}$ to $4.7^{\circ} \mathrm{C}$ for $75^{\circ} \mathrm{C}$. The ED50 temperature value for ophthalmoscopically visible lesions in rabbits was determined as $65.3^{\circ} \mathrm{C}$. The introduced method can be used for retinal irradiations with adjustable temperature elevations. ๑ 2017 Society of Photo-Optical Instrumentation Engineers (SPIE) [DOI: 10.1117/1.JBO.22.11.118001]
\end{abstract}

Keywords: ophthalmology; retinal laser photocoagulation; laser therapy; optoacoustics.

Paper 170297R received May 31, 2017; accepted for publication Oct. 25, 2017; published online Nov. 21, 2017.

\section{Introduction and Background}

Retinal laser photocoagulation is a widely used treatment for peripheral ischemic retinal diseases such as diabetic retinopathy, ischemia due to vein occlusion and other conditions, ${ }^{1-4}$ as well as for treating diabetic macular edema, ${ }^{5}$ either on its own or in combination with pharmacological agents. Since the introduction of antivascular endothelial growth factor (anti-VEGF) therapies, laser photocoagulation has been challenged as the standard treatment, especially for diabetic edema, but still remains a relevant alternative for this indication.

So far, the treating physician has to choose the exposure time and laser beam diameter based on the treatment indication and the laser power according to the ophthalmoscopic evaluation of the appearance of the lesions after treatment. The method of treatment as introduced by Meyer-Schwickerath ${ }^{6}$ has become a standard procedure with the development and application of $\mathrm{Ar}^{+}$-lasers around two decades later. ${ }^{7}$ The laser light, typically in the green spectral range, is absorbed mainly in the retinal pigment epithelium (RPE) and the choroid. Due to heat diffusion, the adjacent retinal layers are thermally denatured, and the result becomes apparent as whitish lesions. Recent trends in the development of this modality have focused on reducing the treatment time. It has been shown that short irradiation times of about $20 \mathrm{~ms}$ can lead to the reduction of axial tissue damage ${ }^{8}$ and reduced pain for the patient during treatment. ${ }^{9}$ This and the desire for a more efficient treatment has led to the development of automated pattern photocoagulation, where each individual

*Address all correspondence to: Alexander Baade, E-mail: alexander.baade@ gmx.net lesion is created within a short timeframe, ${ }^{10}$ typically within 10 to $20 \mathrm{~ms}$. However, the likelihood for overtreatment increases with decreasing treatment duration, due to the reduction of the therapeutic window, ${ }^{11}$ which describes the range of laser powers that lead to visible lesions without causing rupture. This reduction of the therapeutic window can be problematic due to local pigmentation variations up to a factor of three in the absorbing layers $^{12,13}$ as well as age-related variations of the light transmittance through the ocular media, ${ }^{14}$ treatments with the same laser parameters can have a wide variety of outcomes, in extreme cases unnecessarily strong lesions, rupture, and bleeding.

Depending on the indication, the treatment endpoint ranges from small and gentle lesions for diabetic macula edema, typically with lesion sizes around 50 to $100 \mu \mathrm{m}$ to more pronounced lesions for diabetic retinopathy with lesion diameters of up to $500 \mu \mathrm{m}$. However, the mechanism of the therapeutic effect of the treatment is still not fully understood. Hence, the required minimal lesion strength for a positive therapeutic outcome is unknown. This is why researchers have begun studying the dosage threshold of irradiations for clinical viability ${ }^{15,16}$ and started investigating the efficacy of low-dose treatments. ${ }^{17-19}$

Reducing the risk of overly damaging treatment outcomes and reducing pain are major goals in improving the reliability of photocoagulation therapy. With shorter irradiation times, however, this increases the need for an objective measurement of the denaturation effect and a real-time laser exposure control. $^{20}$ Several ideas for reliably creating subvisible or mild treatment effects have been engineered and tested over

1083-3668/2017/\$25.00 @ 2017 SPIE 
the last decade. ${ }^{21,22}$ One approach ("endpoint management") uses titration lesions to determine the laser parameters that lead to a barely visible lesion and uses a mathematical model based on the Arrhenius-theory to adjust the therapy laser power and time for the application of the nondamaging retinal therapy. A clinical trial on patients with central serous retinopathy using this method has shown the clinical efficacy of subvisible laser exposures. ${ }^{23}$

Another approach uses the consecutive application of laser pulse trains in the $100-\mu$ s regime. The treating physician chooses the appropriate laser parameters for the "micropulse" treatment, either from experience or after creating a test burn outside the treatment area. ${ }^{24}$

Both of these mentioned methods rely on predicting the extent of lesions due to a titration process. However, without direct feedback from the tissue, these methods are subject to variations in treatment outcome, due to the variation of the absorption and the associated laser-induced temperature rise variability.

In order to utilize site-individual feedback and automatic dosimetry for the treatment, a temperature-based method using the optoacoustic effect has been introduced. ${ }^{25}$ Optoacoustics provides a noninvasive real-time monitoring of tissue temperature during photocoagulation. Originally developed for use during transpupillary thermotherapy, ${ }^{26}$ the feasibility of the temperature rise measurement was demonstrated on porcine fundus explants,${ }^{27}$ and recently the first temperature monitoring on patients during standard photocoagulation was showcased. ${ }^{28}$ The validity of the temperature measurement was shown using fundus images and optical coherence tomography (OCT) ${ }^{29}$ Using the optoacoustic temperature measurement, a feedback algorithm was developed. The lesion strength depends on the temperature rise and the treatment time, so the method monitors both during the irradiation. Once the threshold temperature for the desired lesion strength at the elapsed time is reached, the laser is switched off automatically. This dosimetry has been successfully demonstrated in vivo in rabbits. ${ }^{25}$ It was achieved by monitoring the temperature increase of the retinal tissue during the photocoagulation at a rate of $1 \mathrm{kHz}$ and automatically stopping the treatment according to a characteristic curve that determines the relation between the temperature and irradiation time. It was shown that the developed algorithm was able to create ophthalmoscopically uniform lesion sizes independent of the laser power, transmission and degree of pigmentation, and showing via histology that the ganglion and nerve fiber layers were reliably unaffected. ${ }^{30}$ The creation of lesions of different strengths was also demonstrated on rabbits in vivo. ${ }^{31,32}$

In this work, we present an alternative approach for a temperature-based feedback control, which adjusts the therapy laser power during the irradiation, in order to achieve a preset temperature rise within a fixed time frame.

\section{Theory}

\subsection{Optoacoustic Temperature Measurement}

The temperature measurement is based on the optoacoustic effect. The temperature-dependent pressure generation is described thoroughly by Brinkmann et al. ${ }^{28}$ If a laser pulse with pulse duration $\tau_{p}$ is applied to an absorber, the absorbed energy $E$ is converted to heat and the temperature of the absorber rises by

$$
\Delta T(z)=\frac{\mu_{a}}{\rho C_{p}(T)} * H(z),
$$

where $H$ is the radiant exposure $H(z)=E(z) / A$ with $A$ the irradiated area. If the irradiation time $\tau_{p}$ is shorter than the pressure relaxation time, the pressure within the absorber rises by $P(z)$. For laser light with a top hat profile and a pulse duration that fulfils the conditions of thermal and stress confinement and for a homogeneous absorber with an absorption coefficient $\mu_{a}$ as well as a negligible scattering, it has been shown that the generated local pressure increase $P(z)$ is proportional to the energy $E(z)$ of the pulsed laser light and the Grüneisen parameter $\Gamma(T)^{33,34}$

$P(z) \propto \Gamma(T) \cdot E(z)$,

where $\Gamma(T)$ is given by

$\Gamma(T)=\frac{\beta(T) \cdot c_{s}(T)^{2}}{C_{P}(T)}$,

where $\beta(T)$ is the thermal expansion coefficient, $c_{s}(T)$ is the speed of sound in the absorber, and $C_{p}(T)$ is the heat capacity. The pressure rise $P(z)$ inside the absorber leads to a thermoelastic expansion proportional to $\Gamma(T)$ and the creation of a bipolar photoacoustic pressure wave according to the acoustic wave equation. ${ }^{33}$ For retinal irradiations, the pressure wave propagates through the eye globe and its amplitude $p(t)$ can be detected at the cornea. Due to absorption and acoustic impedance mismatches of the eye constituents the amplitude is attenuated, however, the detected pressure wave amplitude $p(t)$ is proportional to $\Gamma(T) \cdot E(z)$. Due to the temperature dependency of $\Gamma(T)$, the detected amplitude of the pressure wave $p(t)$ contains information on the base temperature of the irradiated tissue $T$. We can express $\Gamma(T)$ using a second-order polynomial approximation

$\Gamma(T) \propto\left[\left(T^{2}-T_{0}^{2}\right)-2 T_{\max }\left(T-T_{0}\right)\right]$,

where $T_{0}$ indicates the temperature, in which $\Gamma(T)=0$ and $T_{\max }$ is the temperature, in which $\Gamma(T)$ reaches its peak. If we combine Eq.(2), now using the pressure amplitude $p(t)$ as discussed above and Eq. (4) and define $s$ as the combined proportionality constant from these equations, we can derive the temperature by measuring the pressure and solving the combined quadratic equation for $T$. For a uniform temperature of the absorber, the optoacoustically determined temperature $T_{\mathrm{OA}}$ corresponds to the absorber temperature and can be determined by measuring the pressure wave amplitude $p(t)$ using the solution for the quadratic equation ${ }^{26}$

$T_{\mathrm{OA}}(t)=T_{\max }-\sqrt{T_{\max }^{2}+\frac{p(t)}{s \cdot E}+T_{0}^{2}-2 T_{\max } T_{0}}$.

$T_{0}$ and $T_{\max }$ are the tissue specific parameters that were determined for rabbits by a calibration measurement of the optoacoustical signal for known temperatures ${ }^{26}$ as $T_{0}=-17.4^{\circ} \mathrm{C} \pm$ $0.3^{\circ} \mathrm{C}$ and $T_{\max }=102.9^{\circ} \mathrm{C} \pm 2.2^{\circ} \mathrm{C}$.

The proportionality constant $s$ is unique for each irradiation site and contains information of the pigmentation at each irradiated area, but also on the light and sound transmission through the eye as well as the detector characteristics. It is, therefore, required to determine $s$ for each individual irradiation site prior to the application of the therapy laser radiation. If one measures the pressure $p\left(t, T_{\text {ref }}\right)$ at a known temperature $T_{\text {ref }}$, in this case the body temperature during in vivo experiments, Eq. (5) can be solved for $s$. This step allows us to take the site-individual variations in signal into account. 


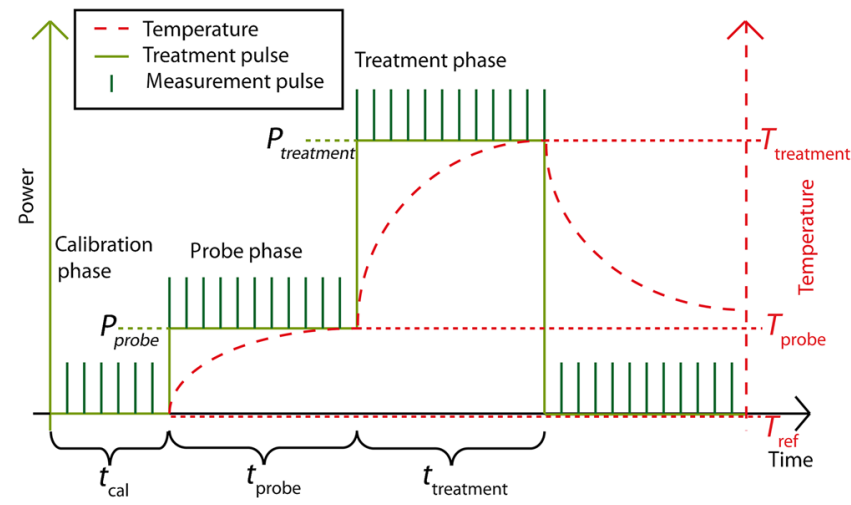

Fig. 1 Irradiation scheme for the power-controlled dosimetry. After a calibration phase, a probe irradiation at a low power $P_{\text {probe }}$ is conducted to reveal the tissue parameters. The probe temperature $T_{\text {probe }}$ is measured and used to calculate the necessary power for the treatment irradiation $P_{\text {treatment }}$ in order to create the treatment temperature $T_{\text {treatment }}$.

\subsection{Power-Controlled Retinal Photocoagulation}

In order to perform irradiations within a set time frame with a fixed desired end temperature $T_{\text {aim }}$, the laser power during the photocoagulation is adjusted depending on the site-individual temperature information. This is shown in Fig. 1.

Each irradiation consists of three phases. In the calibration phase of duration $t_{\text {cal }}$, calibration pulses are applied to the unheated fundus tissue in order to determine the irradiation site specific parameter $s$. This calibrates the feedback signal to the base temperature of the absorber before the start of the treatment $T_{\text {ref }}$ (here, the body temperature of the rabbit for the in vivo experiments). After the calibration, an irradiation at a low power $P_{\text {probe }}$ is performed for an irradiation time $t_{\text {probe }}$, during which the temperature rise $T_{\text {probe }}$ is monitored. The knowledge of $T_{\text {probe }}$ and $P_{\text {probe }}$ can be used to calculate the required power $P_{\text {treatment }}$ to reach the desired temperature rise $T_{\text {aim }}$. The tissue is irradiated with the calculated treatment laser power $P_{\text {treatment }}$ and the irradiation time $t_{\text {treatment }}$, and the temperature reaches $T_{\text {treatment }}$ in order to create the desired lesion strength at the end of the irradiation.

\subsection{Temperature Profile During Retinal Photocoagulation}

When heating the rabbit fundus, the radiation is absorbed in the monolayer melanin granules of the RPE and the pigmented part and blood of the choroid. As the rabbit is a merangiotic animal, the blood vessels are confined to these regions and the absorption in the inner retina can be neglected. A model for rabbit eyes with absorption coefficients of $\mu_{a}=1204$ and $260 \mathrm{~cm}^{-1}$ with thicknesses 4 (absorbing part of the RPE) and $30 \mu \mathrm{m}$ (absorbing part of the choroid), respectively, ${ }^{35}$ was used for the calculations. According to the heat diffusion equation

$\rho C_{P} \frac{\partial \Delta T(\vec{r}, t)}{\partial t}-\nabla \cdot[k \cdot \nabla \Delta T(\vec{r}, t)]=Q(\vec{r}, t)$,

where $\rho$ is the density of the medium, $C_{p}$ is the heat capacity at constant pressure, and $k$ is the thermal conductivity, the temperature $\Delta T(\vec{r}, t)$ in the surrounding media will also increase. The " $\Delta$ " denotes that we are considering the temperature rise only with respect to the base temperature $T_{\text {ref }}$, which for this work is the body temperature of the rabbit. The heat diffusion creates a temperature profile that varies spatially and temporally. Similarly, when probing with a short-laser pulse, the optoacoustic pressure waves will be excited in the RPE and choroid, with amplitude according to the base temperature and remaining light intensity at each absorber. As the temperature profile varies radially and axially, each absorbing volume element gives rise to a pressure wave according to the temperature rise $\Delta T(\vec{r}, t)$ at its location. The optoacoustic approach, therefore, describes the average depth weighted temperature of the irradiated volume $\Delta T_{\text {volume }}(t)$

$\Delta T_{\text {volume }}(t)=\mu_{a} \int_{0}^{\infty}\left[\Delta T_{\text {mean }}(t, z) \cdot e^{-\mu_{\mathrm{a}} z}\right] \mathrm{d} z$.

The mean temperature of each layer $\Delta T_{\text {mean }}(t, z)$

$\Delta T_{\text {mean }}(t, z)=\frac{1}{A} \int_{-R}^{R} \int_{-R}^{R} \Delta T(t, x, y, z) \mathrm{d} x \mathrm{~d} y$,

is weighed with the remaining pulse energy in the depth $z$, which is attenuated according to Beer's law, ${ }^{28}$ with $A$ the area of irradiation.

However, $T_{\text {volume }}(t)$ is not a suitable parameter to describe the coagulation process. The peak RPE surface temperature of the irradiated volume $T_{\text {peak }}(t)$, which is located at the center of the irradiated area close to the surface of the RPE, provides a better description, as it determines the onset of the retinal coagulation. $\Delta T_{\text {peak }}(t)$ is correlated to $\Delta T_{\text {volume }}(t)$ via a timedependent conversion function

$f(t)=\frac{\Delta T_{\text {peak }}(t)}{\Delta T_{\text {volume }}(t)}$,

which can be obtained by modeling the temperature profile of the heating process. If we assume that $\Delta T_{\text {volume }}(t)$ corresponds to the optoacoustically determined temperature rise $\Delta T_{\mathrm{OA}}(t)$, then $\Delta T_{\text {peak }}(t)$ is given by

$\Delta T_{\text {peak }}(t)=\Delta T_{\mathrm{OA}}(t) \cdot f(t)$

The conversion function and its properties are described in detail by Schlott et al. ${ }^{25}$ and the radial and axial temperature profiles are more thoroughly investigated by Brinkmann et al. ${ }^{28}$ Hence, only the adjustments that are necessary for this method are described here.

For the power-controlled irradiation, the conversion function is not just one continuous function but has to be determined for the probe phase and the treatment phase independently. We used a mathematical model to derive $f(t)$ for the two irradiation phases at the rabbit fundus. The commercially available software COMSOL Multiphysics 4.2 is a finite-element numerical simulation software, which was used here to solve the heat diffusion equation [Eq. (6)]. The light-tissue interaction is not modeled directly but rather treated as a heat source $Q(\vec{r}, t)$, which describes the laser energy deposition per time and volume in $\mathrm{W} / \mathrm{m}^{3}$ and can be described within the irradiated volume during the irradiation as 
Table 1 Layer thicknesses and absorption coefficients of the rabbit fundus as used in the numerical model.

\begin{tabular}{lcc} 
Layer & $\begin{array}{c}\text { Thickness } \\
(\mu \mathrm{m})\end{array}$ & $\begin{array}{c}\text { Absorption } \\
\text { coefficient }\left(\mathrm{cm}^{-1}\right)\end{array}$ \\
\hline Retina & 190 & 0 \\
Pigmented part of RPE & 4 & 1204 \\
Unpigmented part of RPE/choroid & 37 & 0 \\
Absorbing part of choroid & 20 & 260 \\
\hline
\end{tabular}

$Q(\vec{r}, t)=Q(z)=\frac{P_{L}}{d^{2}} \mu_{a} e^{-\mu_{a} z}$,

where $d$ is the edge length of the (square) irradiated area and $P_{L}$ is the laser power. The layer thicknesses were chosen according to Birngruber et al. ${ }^{34}$ and the absorption coefficients $\mu_{a}$ according to Hammer ${ }^{35}$ as shown in Table 1.

Light scattering is not incorporated in the model. The geometry is more thoroughly discussed by Schlott et al. ${ }^{25}$ and shown in Fig. 2(a). The origin $(x, y, z)=(0,0,0)$ is at the center of the square irradiated area at the surface of the RPE. The temperature rise is shown for the end of the treatment at $t=50 \mathrm{~ms}$ with a calibration power $P_{\text {cal }}=3 \mathrm{~mW}$ (which corresponds to a pulse energy of $3 \mu \mathrm{J}$ applied with a repetition rate of $1 \mathrm{MHz}$ ), a probe power $P_{\text {probe }}=10 \mathrm{~mW}$ and a treatment laser power $P_{\text {treatment }}=$ $20 \mathrm{~mW}$ in a vertical $x$-z-slice through the fundus layers, where $x$ is one of the radial coordinates and $z$ is the axial coordinate with the upper edge of the RPE located at $z=0$. The axial temperature profile development over time (b) as well as the profile in $x$-direction (c) is also shown.
In the model, the remaining tissue parameters are assumed to be that of water $\left[\rho=993 \mathrm{~kg} / \mathrm{m}^{3} ; C_{p}=4176 \mathrm{~J} /(\mathrm{kg} \mathrm{K})\right.$; $k=0.627 \mathrm{~W} /(\mathrm{m} \mathrm{K})]$. The temporal temperature development of $\Delta T_{\text {peak }}$ and $\Delta T_{\text {volume }}$ as calculated from the temperature profiles is shown in Fig. 3.

For the experiments, we used a fiber with a square core, so the integration in Eq. (7) was carried out in carthesian coordinates. This also necessitates the simulation being run in three-dimensions, because there is no radial symmetry. The simulation parameters were chosen to be $P_{\text {calibration }}=3 \mathrm{~mW}$ which corresponds to a pulse energy of $3 \mu \mathrm{J}$ applied with a repetition rate of $1 \mathrm{MHz}, P_{\text {probe }}=10 \mathrm{~mW}, P_{\text {treatment }}=20 \mathrm{~mW}$ and $d=200 \mu \mathrm{m}$. By taking the ratio of $\Delta T_{\text {peak }}$ and $\Delta T_{\text {volume }}$ according to Eq. (9), one can determine the conversion function $f(t)$. We split the conversion function into two parts, $f_{\text {probe }}(t)$ and $f_{\text {treatment }}(t)$, corresponding to the probe and treatment phase, respectively.

From Fig. 1, the ratio of powers $P_{\text {treatment }} / P_{\text {probe }}$ can be correlated to the ratio of temperatures $\Delta T_{\text {treatment }} / \Delta T_{\text {probe }}$. If the tissue was allowed to cool down to $\Delta T_{\text {ref }}$ prior to applying $P_{\text {treatment }}$, then $P_{\text {treatment }} / P_{\text {probe }}=\Delta T_{\text {treatment }} / \Delta T_{\text {probe }}$, because the temperature rise is proportional to the introduced heat. ${ }^{36}$ However, if the temperature is not completely cooled down when the treatment phase starts, $f$ becomes a function of the spot size used, the time of the probe phase and the time gap to the start of the treatment phase. Therefore, we used the mathematical model to calculate the relationship between the ratios. The temperature rise from the two successive phases was simulated by varying the laser powers $P_{\text {probe }}$ and $P_{\text {treatment }}$ for different beam diameters and calculating the temperatures. By plotting $\Delta T_{\text {treatment }} / \Delta T_{\text {probe }}$ over $P_{\text {treatment }} / P_{\text {probe }}$, we found a linear correlation that could be fitted according to $\Delta T_{\text {treatment }} / \Delta T_{\text {probe }}=m * P_{\text {treatment }} / P_{\text {probe }}+b$, where $m$ is the (a)
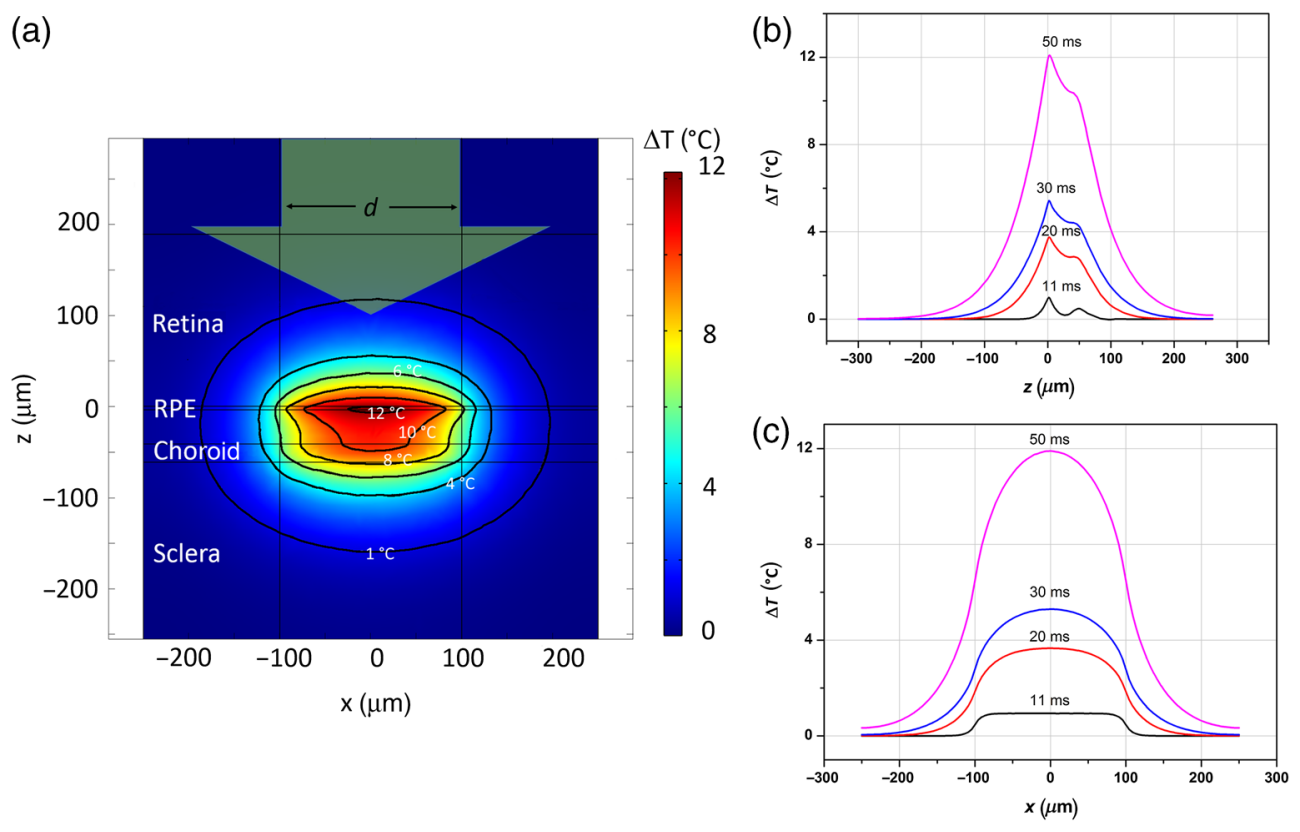

Fig. 2 Fundus layer geometry and temperature distribution for the temperature simulation on the rabbit fundus, displayed for (a) a vertical slice through the rabbit fundus with isothermal contours indicating the regions with a temperature rise of $1,4,6,8,10$ and $12^{\circ} \mathrm{C}$, (b) along the $z$-axis, and (c) on the surface of the RPE along the $x$-direction for $1,10,20$, and $40 \mathrm{~ms}$ after the calibration phase, which corresponds to $t=11$, 20,30 , and $50 \mathrm{~ms}$, respectively. The displayed temperature profile occurs at the end of the treatment at $\mathrm{t}$ $=50 \mathrm{~ms}$. The edge length of the irradiation beam (arrow) is $d=200 \mu \mathrm{m}$. 


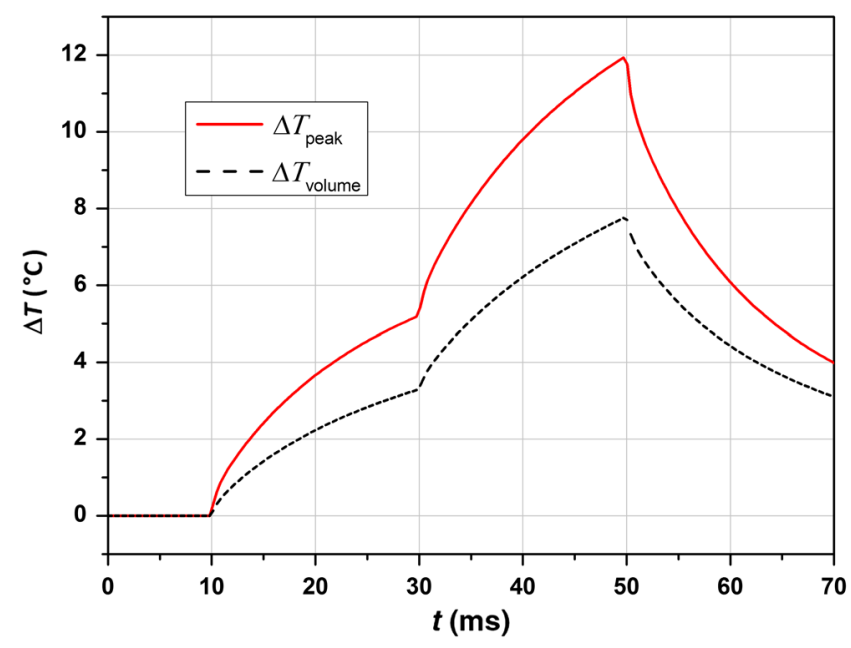

Fig. 3 Simulation results for $\Delta T_{\text {peak }}(t)$ (solid line) and $\Delta T_{\text {volume }}(t)$ (dashed line) over the course of an entire irradiation, consisting of 10-ms calibration phase, 20-ms probe phase, and 20-ms treatment phase. $P_{\text {probe }}$ was chosen as $10 \mathrm{~mW}$ and $P_{\text {treatment }}$ was chosen as $20 \mathrm{~mW}$.

slope of the curve and $b$ is the intersection with the temperature axis. We found $m=1$ for all diameters, but the intersection was radius-dependent, as is shown in Fig. 4. The simulated data were fitted with a parabola.

The powers $P_{\text {probe }}$ and $P_{\text {treatment }}$ consist of the laser power of the therapy beam $P_{\text {th }}$ and the mean power introduced by the measurement laser pulses $P_{\text {pulse }}\left(P_{\text {probe }}=P_{\text {probe,th }}+P_{\text {probe,pulse }}\right.$, $\left.P_{\text {treatment }}=P_{\text {treatment, th }}+P_{\text {treatment,pulse }}\right) . P_{\text {pulse }}$ remains the same for the successive irradiations $\left(P_{\text {probe,pulse }}=P_{\text {treatment,pulse }}=\right.$ $\left.P_{\text {pulse }}\right)$. Using this and solving for $P_{\text {treatment,th yields }}$

$$
\begin{aligned}
P_{\text {treatment,th }}= & \left(\frac{T_{\text {treatment }}-T_{\text {ref }}}{T_{\text {probe }}-T_{\text {ref }}}-b\right) *\left(P_{\text {probe }, \text { th }}+P_{\text {Pulse }}\right) \\
& -P_{\text {Pulse }}
\end{aligned}
$$

In the experiments, we exclusively used a beam diameter of $200 \mu \mathrm{m}$, so we find $b=0.37$ for our setup.

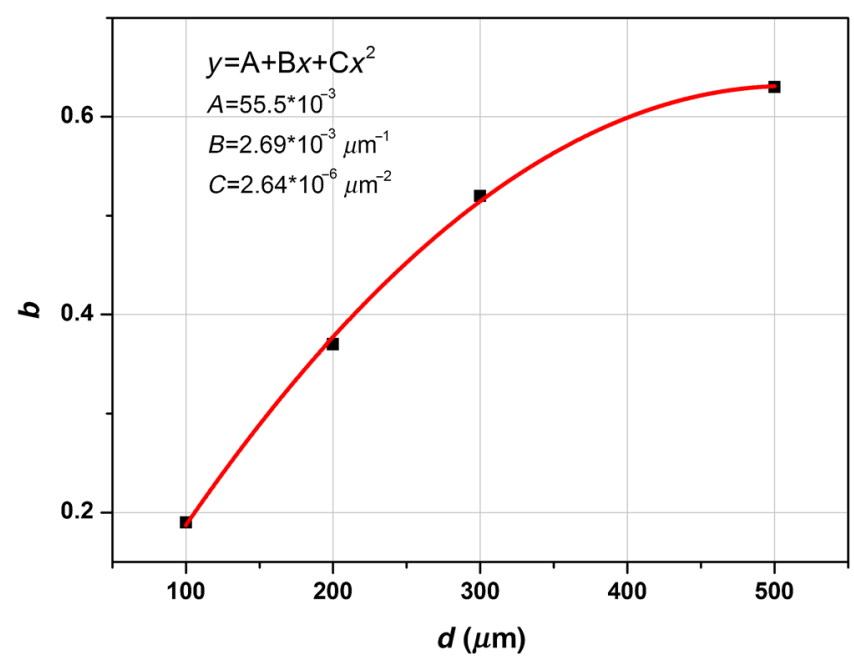

Fig. 4 Irradiation diameter dependency of the intersection $b$ for the linear approximation between the ratio of temperature rises and the laser powers.

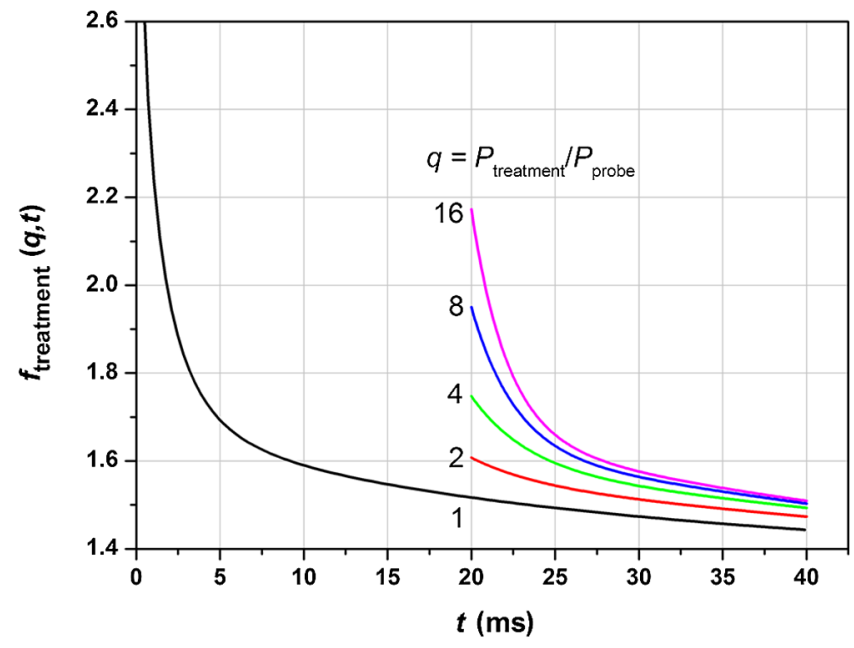

Fig. 5 Conversion functions $f_{\text {treatment }}$ for the treatment phase for different ratios of $P_{\text {probe }}$ and $P_{\text {treatment }}$.

$P_{\text {treatment,th }}$ is the power that is required during the treatment phase in order to reach $T_{\text {aim }}$ at the end of the treatment phase. Of particular interest is the conversion function $f_{\text {treatment }}(q, t)$ for different ratios of laser powers $q=P_{\text {probe }} / P_{\text {treatment }}$. This is depicted in Fig. 5. After calculating $P_{\text {treatment }}$, the temperature is monitored using the corresponding conversion function based on $q$.

\section{Materials and Methods}

\subsection{Experimental Setup}

The experimental setup is shown in Fig. 6. The therapy laser is a frequency doubled Nd:YAG (Visulas $532 \mathrm{~s}$, Carl Zeiss Meditec AG, $\lambda=532 \mathrm{~nm}, \mathrm{cw}$ ). After starting the irradiation via a footswitch, the PC opens the shutter that blocks the measurement laser radiation (Uniblitz LS6, aperture $6 \mathrm{~mm}$, time to open: $0.7 \mathrm{~ms}$ ). The temperature measurement is performed using light from a frequency doubled Q-switched Nd:YLF laser (QC-5231000 , CrystaLaser, $\lambda=523 \mathrm{~nm}, \tau=75 \mathrm{~ns}, f=1 \mathrm{kHz}$ ), which emits one pulse every millisecond. The radiation is coupled via a microscope objective into a multimode fiber (square core with edge length $d=70 \mu \mathrm{m}, \mathrm{NA}=0.11$ ). The fiber is connected to a laser slit lamp (LSL 532s, Carl Zeiss Meditec AG), which guides the light through a contact lens. The lens is a modified commercial lens (Mainster Focal Grid, OMRA-S, Oculus Instruments) with a laser spot magnification of 1.05 into which an annular piezoceramic ultrasonic transducer with a center frequency of $f_{\mathrm{p}}=1 \mathrm{MHz}$ and a bandwidth of $410 \mathrm{kHz}$ was embedded to detect the incident pressure waves. The light is then focused onto the rabbit fundus for the irradiation. The measurement light induces the optoacoustic ultrasound waves from the retinal layers, which travel through the ocular media and reach the contact lens with the embedded transducer, where they are converted into electrical signals that are amplified and recorded via a digitizer card (CompuScope 8347, Gage Applied Technologies). The data processing and feedback control are performed by a custom made LabVIEW routine. The measured pressure provides the temperature information according to Eq. (5).

The light from the therapy laser after opening the shutter (Uniblitz LS6) is superimposed with the light from the measurement laser and both are coupled into the fiber. This way the measurement irradiation is guaranteed to irradiate the same 


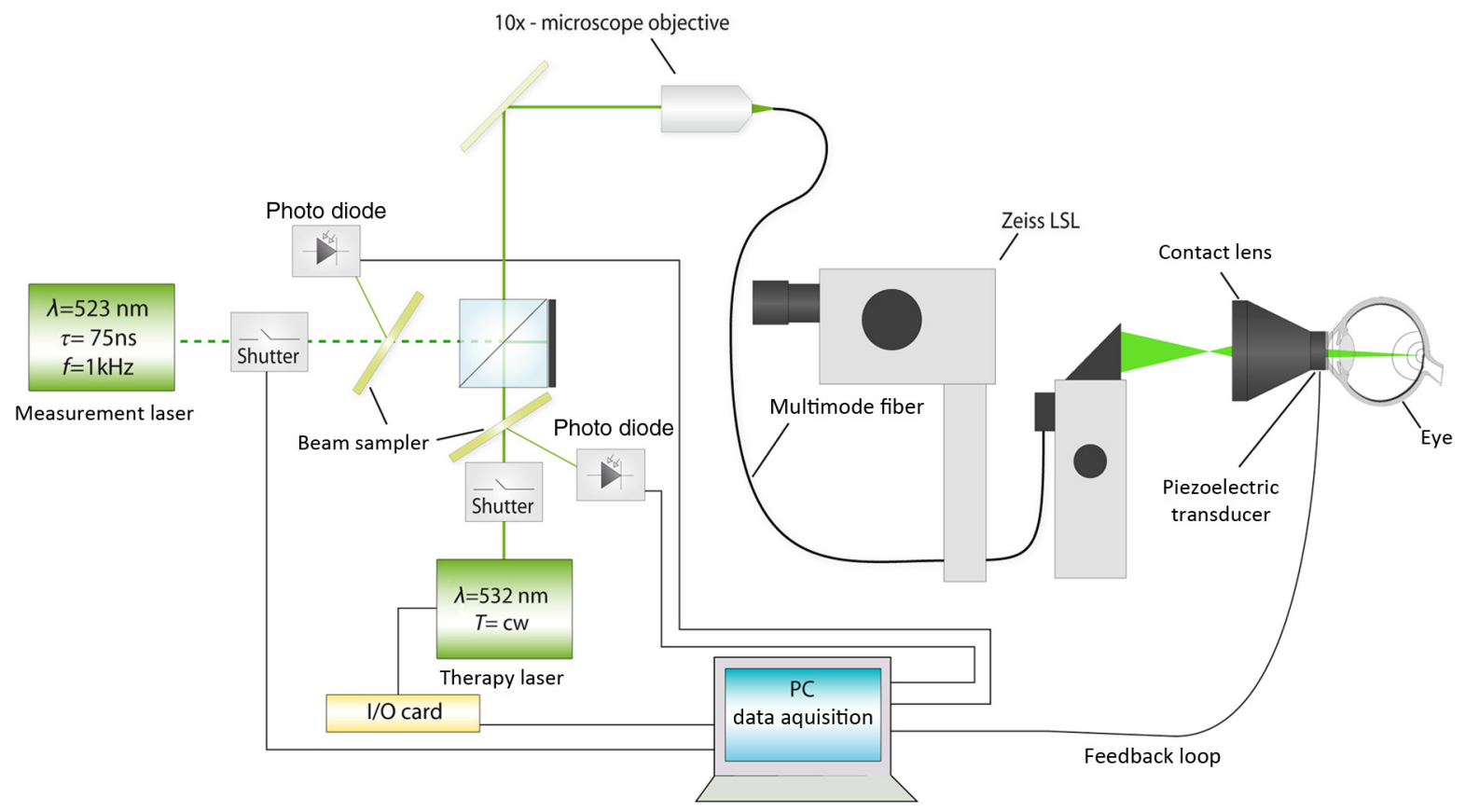

Fig. 6 Set-up for the power-controlled retinal photocoagulation.

volume as the therapy irradiation. The laser power is controlled using an input/output card (NI PCIe-6341, National Instruments) to perform the treatment during the treatment phase.

\subsection{Animal Model}

The experiments on chinchilla gray rabbits in vivo were carried out according to the German law for protection of animals, approved by the Ministry of Agriculture, the Environment and Rural Areas of Schleswig-Holstein, Kiel, Germany. Prior to the irradiation, the rabbits were anesthetized using ketamine $\left(10 \%, 0.5\right.$ to $\left.0.7 \mathrm{~mL} \cdot \mathrm{kg}^{-1}\right)$ and xylazine $(2 \%, 0.2$ to $\left.0.25 \mathrm{~mL} \cdot \mathrm{kg}^{-1}\right)$.

\subsection{Treatment Scheme}

After the animal was narcotized, it was fixed in a custom-made holding device in front of the slit lamp. The modified contact lens was placed on the rabbit's eye and mechanically fixed. In order to adapt the acoustical and optical properties of the contact lens and cornea, methylcellulose gel (2\%) was used as a contact gel. The body temperature was measured rectally. The beam edge length was set to $300 \mu \mathrm{m}$ on the slit lamp, which results in a beam edge length of $d=200 \mu \mathrm{m}$ on the rabbit fundus. The calibration phase time was chosen to be $t_{\mathrm{cal}}=10 \mathrm{~ms}$ and the probe and treatment phase times were both set to $t_{\text {probe }}=t_{\text {treament }}=20 \mathrm{~ms}$, bringing the resulting total irradiation time per site to $50 \mathrm{~ms}$. During the calibration phase, the shutter for the therapy laser remains closed and was opened at the beginning of the probe phase. The therapy laser power during the probe phase $P_{\text {probe,th }}$ was chosen so that $T_{\text {probe }}$ at the end of the probe phase was $\sim 45^{\circ} \mathrm{C}$. This ensured that the temperature rise during the probe phase would not result in irreversible coagulation effects of the tissue, while at the same time ensuring that the temperature rise is above noise level and can be fitted well. The therapy laser radiation heats the fundus tissue and the resulting temperature curve during the probe phase is fitted with a curve as described by Schlott et al. ${ }^{25}$ to determine $T_{\text {probe }}$, which is then used to determine the required laser power during the treatment phase $P_{\text {treatment,th. The calculation of }}$ $P_{\text {treatment,th }}$ and the adjustment of the therapy laser can be carried out within $<1 \mathrm{~ms}$ during the irradiation. The aim temperatures were chosen as $50^{\circ} \mathrm{C}, 55^{\circ} \mathrm{C}, 60^{\circ} \mathrm{C}, 65^{\circ} \mathrm{C}, 70^{\circ} \mathrm{C}$, and $75^{\circ} \mathrm{C}$. For the first five rabbits (group 1), only the aim temperatures of $50^{\circ} \mathrm{C}$, $55^{\circ} \mathrm{C}, 65^{\circ} \mathrm{C}$, and $75^{\circ} \mathrm{C}$ were used in order to find the ED50 value for ophthalmoscopic visibility. Two additional rabbits (group 2) were irradiated with the aim temperatures $60^{\circ} \mathrm{C}, 65^{\circ} \mathrm{C}, 70^{\circ} \mathrm{C}$, and $75^{\circ} \mathrm{C}$ to resolve the ED50 value more thoroughly. The measurement pulse energy was adjusted between 3 and $5 \mu \mathrm{J}$, depending on the quality of the pressure signal. The measurement pulse energy has to be high enough in order to create a strong photoacoustic signal, but at the same time low enough to prevent it from noticeably heating the tissue during the calibration phase. While the exposure to the measurement pulses in this case is above the threshold values for the maximum permissible exposure, the applied energy does not lead to a denaturation of the tissue that would influence the measurement of the temperature. Regardless, the mean power of the pulses has to be considered for the following therapy as shown in Eq. (12).

In order to evaluate the visibility of the lesions, fundus images were taken $1 \mathrm{~h}$ after the treatment using a fundus camera (VISUCAM $^{\circledR}$, Carl Zeiss Meditec AG). The visibility of the lesion was judged from these fundus images by four independent observers. The lesion was classified as "visible" (1), if three of four observers agreed on seeing the lesion and as "invisible" (0) otherwise.

\section{Results}

\subsection{Accuracy of Aim Temperatures}

The distribution of the final treatment temperatures $T_{\text {treatment }}$ and the corresponding irradiation powers $P_{\text {treatment,th }}$ are shown in Table 2 and displayed with their standard deviations $\sigma_{T}$ and 
Table 2 Aim temperatures, measured treatment temperatures, corresponding treatment powers, and number of irradiations for the power-controlled coagulations.

\begin{tabular}{lcccccc}
$T_{\text {aim }}\left({ }^{\circ} \mathrm{C}\right)$ & $T_{\text {treatment }} \pm \sigma_{T}\left({ }^{\circ} \mathrm{C}\right)$ & $\sigma_{\text {rel }, T}(\%)$ & $P_{\text {treatment,th }} \pm \sigma_{P}(\mathrm{~mW})$ & $\sigma_{\text {rel, }, P}(\%)$ & $N$ & Standard error $\left({ }^{\circ} \mathrm{C}\right)$ \\
\hline 50 & $49.3 \pm 2.1$ & 18.4 & $25.4 \pm 7.8$ & 30.7 & 100 & 0.21 \\
55 & $54.7 \pm 3.5$ & 21.2 & $45.7 \pm 19.4$ & 42.4 & 232 & 0.23 \\
60 & $60.4 \pm 4.0$ & 18.1 & $57.1 \pm 19.2$ & 33.6 & 71 & 30.4 \\
65 & 11.4 & $80.0 \pm 24.4$ & 30.6 & 25.3 & 69 & 0.18 \\
70 & $65.1 \pm 3.1$ & 15.5 & $76.9 \pm 19.5$ & 32.2 & 229 & 0.6 \\
75 & $70.5 \pm 5.0$ & 11.7 & $109.0 \pm 35.0$ & & & \\
\hline
\end{tabular}

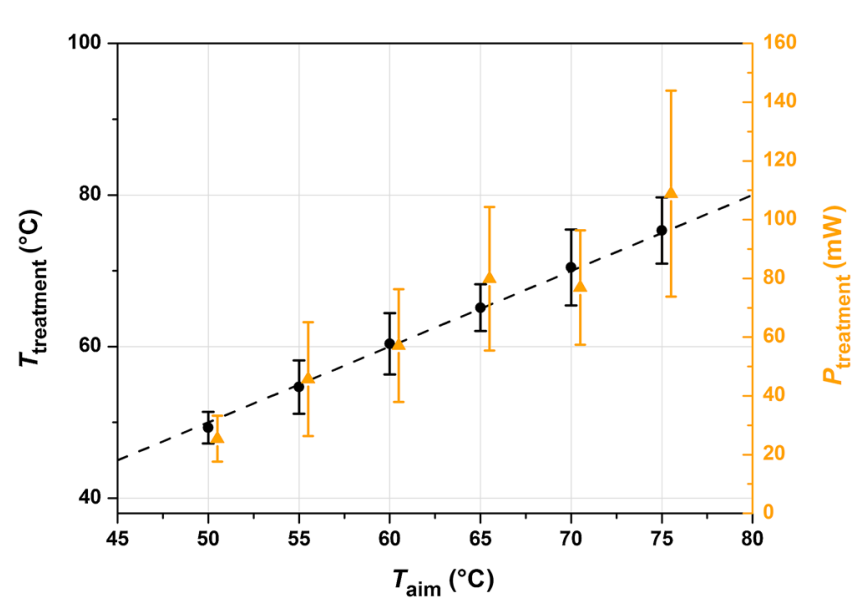

Fig. 7 Power control treatment temperatures and laser powers. The dots denote the mean value of the temperatures at the end of the treatment with their respective standard deviations. The triangles show the mean value of the treatment phase therapy laser power for each aim temperature with their respective standard deviations $\sigma_{T}$ and $\sigma_{P}$. The symbols for the powers are shifted slightly to improve visibility.

$\sigma_{P}$, respectively, in Fig. 7, as well as the standard error for $T_{\text {treatment }} \sigma / \sqrt{N}$. The end temperatures of $N_{\text {total }}=1001$ irradiations could be evaluated. To better compare the standard deviations of the temperature and the laser powers, the relative deviation $\sigma_{\text {rel }}$ for both is given in $\%$. For the temperature, one has to consider the error on the temperature rise $\Delta T_{\text {treatment }}=T_{\text {treatment }}-T_{\text {ref }}$ in accordance to Eq. (12), so the relative error $\sigma_{\text {rel, } T}$ is, therefore, given as $\sigma_{T} / \Delta T_{\text {treatment }}$ with $T_{\text {ref }}=38^{\circ} \mathrm{C}$. There is no such offset for the power, so $\sigma_{\text {rel }, P}$ is simply $\sigma_{P} / P_{\text {treatment,th. The dashed line in Fig. } 7 \text { represents }}$ the bisecting line through the origin for the temperature axis, that is, the line on which the measured temperatures should fall.

The mean measured temperatures (dots) agree very well with the target values (dashed line). The standard deviation of the temperatures increases with higher aim temperatures. For all temperatures, the corresponding treatment laser powers $P_{\text {treatment }}$ (triangles) show a larger standard deviation than the temperatures (about twice the relative deviation), indicating that the algorithm used laser powers over a wide range to reach the desired end temperature.

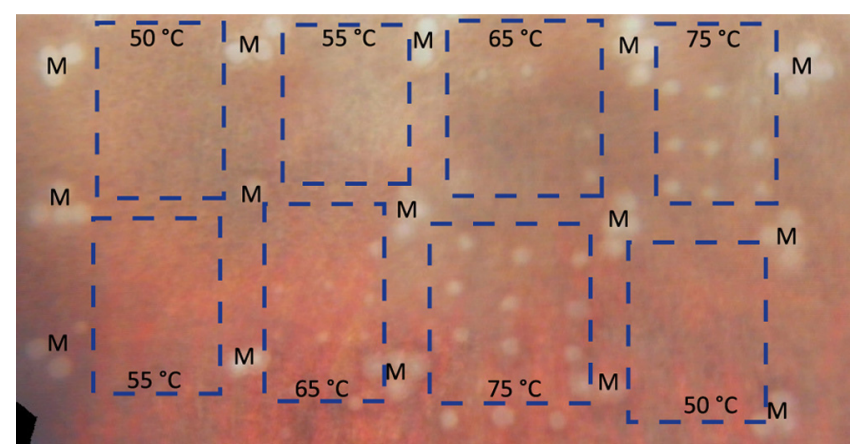

Fig. 8 Fundus image of power-controlled irradiation sites in vivo for $T_{\text {aim }}=50^{\circ} \mathrm{C}, 55^{\circ} \mathrm{C}, 65^{\circ} \mathrm{C}$, and $75^{\circ} \mathrm{C}$. Marker lesions for orientation are marked as "M."

\subsection{Visibility Threshold of Irradiations}

Figure 8 shows a fundus image of the power-controlled irradiation sites for the different aim temperatures taken $1 \mathrm{~h}$ after the end of the irradiation for one of the rabbits from group 1, Fig. 9 shows the same for one of the rabbits from group 2. The images show the appearance of the irradiation sites for the different aim temperatures.

Visible lesions appear as white areas due to the increased scattering of the coagulated tissue. The bright white lesions

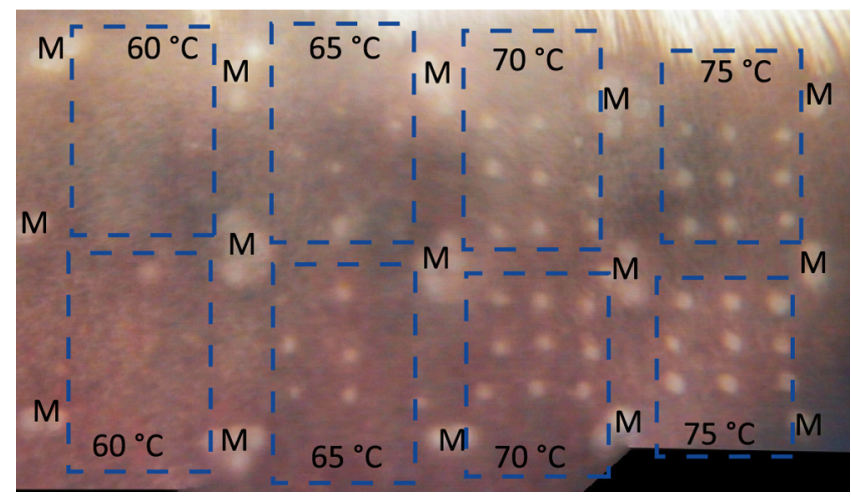

Fig. 9 Fundus image of power-controlled irradiation sites in vivo for $T_{\text {aim }}=60^{\circ} \mathrm{C}, 65^{\circ} \mathrm{C}, 70^{\circ} \mathrm{C}$, and $75^{\circ} \mathrm{C}$. Marker lesions for orientation are marked as "M." 
Table 3 Number of evaluable irradiation areas $N_{\text {irr }}$ and the number of visible lesions among them for each $T_{\text {aim }}$.

\begin{tabular}{lcccccc}
$T_{\text {aim }}$ & $50^{\circ} \mathrm{C}$ & $55^{\circ} \mathrm{C}$ & $60^{\circ} \mathrm{C}$ & $65^{\circ} \mathrm{C}$ & $70^{\circ} \mathrm{C}$ & $75^{\circ} \mathrm{C}$ \\
\hline$N_{\text {irr }}$ & 66 & 198 & 70 & 280 & 66 & 239 \\
Visible lesions & 0 & 3 & 18 & 119 & 59 & 232 \\
\% visible lesions & 0 & 1.5 & 25.7 & 42.5 & 89.4 & 97.1 \\
\hline
\end{tabular}

marked with an "M" are marker lesions that are used for orientation. Within a square that is formed by four marker lesion areas, nine study irradiations with the same $T_{\text {aim }}$ were performed.

The irradiation sites for $T_{\text {aim }}=50^{\circ} \mathrm{C}$ and $55^{\circ} \mathrm{C}$ almost exclusively show no visible coagulation effects and the irradiation sites for $60^{\circ} \mathrm{C}$ and $65^{\circ} \mathrm{C}$ are in the transition regime between invisible and visible effects, where the $60^{\circ} \mathrm{C}$ mostly remain invisible and the majority of the $65^{\circ} \mathrm{C}$ lesions become visible as mild coagulations. The irradiation sites for $70^{\circ} \mathrm{C}$ and $75^{\circ} \mathrm{C}$ are almost exclusively visible and are more pronounced than the lesions for $60^{\circ} \mathrm{C}$ and $65^{\circ} \mathrm{C}$. The intensity of those lesions is compatible with the current clinical treatment recommendation for panretinal photocoagulation treatment.

The visibility for each $T_{\text {aim }}$ is presented in Table 3 . The number of irradiation areas where the visibility could be evaluated $N_{\text {irr }}$ is compared to the number of visible irradiation outcomes for each aim temperature $T_{\text {aim }}$. The fraction of these two values is given in $\%$.

The evaluation of the visibility of the lesions from the fundus images and the corresponding temperatures can be used to find the ED50 value for ophthalmoscopical visibility, which is the temperature at which there is a $50 \%$ probability that the lesion becomes visible. The value is determined by performing a probit analysis of the binary data (visible and invisible) of the lesions. The result can be seen in Fig. 10, the visible lesions are indicated as black crosses in the top row, and the invisible lesions are at the bottom of the graph.

A total of 920 lesions in 11 eyes of 7 rabbits was evaluated. The number is lower than the number of irradiated sites, as not

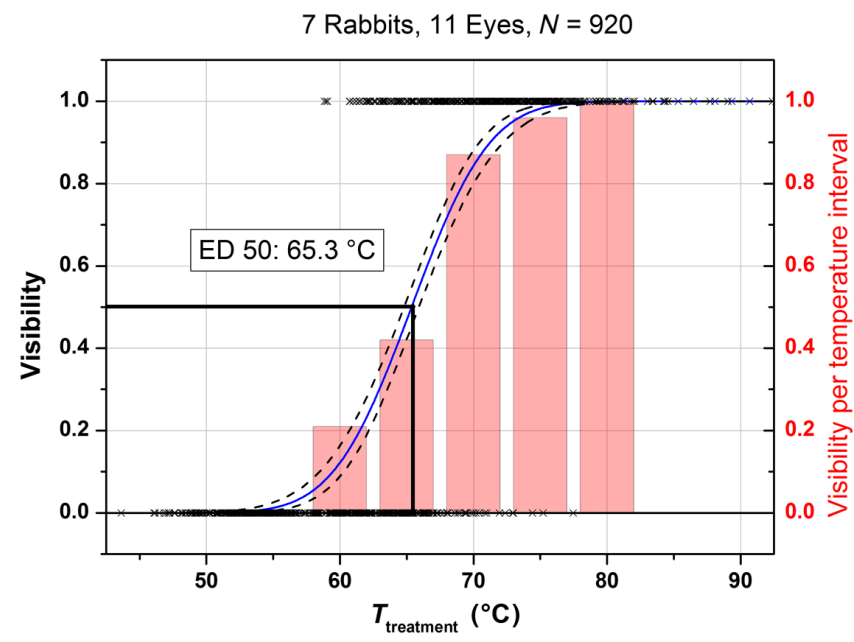

Fig. 10 Probit-plot evaluation of the ED50 value for ophthalmoscopical visibility $1 \mathrm{~h}$ after irradiation.
Table 4 Total number and fraction of visible lesions in a temperature interval of $5^{\circ} \mathrm{C}$ centered on $T_{\mathrm{c}}$.

\begin{tabular}{lccccccc}
$T_{\mathrm{c}}$ & $50^{\circ} \mathrm{C}$ & $55^{\circ} \mathrm{C}$ & $60^{\circ} \mathrm{C}$ & $65^{\circ} \mathrm{C}$ & $70^{\circ} \mathrm{C}$ & $75^{\circ} \mathrm{C}$ & $80^{\circ} \mathrm{C}$ \\
\hline$N_{\text {int }}$ & 88 & 155 & 122 & 199 & 150 & 140 & 38 \\
Visible lesions & 0 & 0 & 26 & 84 & 130 & 135 & 38 \\
$\%$ visible lesions & 0 & 0 & 21.3 & 42.4 & 86.7 & 96.4 & 100.0 \\
\hline
\end{tabular}

all areas could be imaged with the camera. Additionally, we omitted regions where image quality was too poor to give reliable results. The probit curve is displayed as the solid line, the ED50 value was calculated to be $65.3^{\circ} \mathrm{C}$ with a $95 \%$ confidence interval (indicated by the dashed lines). As the total number of visible and invisible lesions is difficult to assess from the graph, as the crosses conceal each other, the density of the visibility is shown for distinct temperature intervals (bars). The bar graph shows the normalized visibility per temperature interval, i.e., the number of visible lesions divided by the total number of irradiations in a temperature interval $N_{\text {int }}$, where $T_{\mathrm{c}}$ is the temperature the bar is centered on, with a temperature range of $\pm 2.5^{\circ} \mathrm{C}$. For example, the bar centered at $T_{\mathrm{c}}=60^{\circ} \mathrm{C}$ represents the fraction of visible lesions among the total irradiations, where $T_{\text {treatment }}$ was measured between $57.5^{\circ} \mathrm{C}$ and $62.5^{\circ} \mathrm{C}$. The numerical values for these visibility fractions for the temperature intervals of $50^{\circ} \mathrm{C}$ to $80^{\circ} \mathrm{C}$ are shown in Table 4 .

\section{Discussion}

\subsection{Accuracy of the Power Controlled Temperature Dosimetry}

Figures 8 and 9 show the fundus image of the irradiations for different aim temperatures. Most of the irradiations with the aim temperatures $T_{\text {aim }}$ of $50^{\circ} \mathrm{C}$ and $55^{\circ} \mathrm{C}$ remained subvisible (261 out of 264), despite a wide range of treatment powers $P_{\text {treatment }}$. This shows that the site-individual absorption was accounted for and provides a reliable option to perform treatments with subvisible outcome. The breakdown into each category is shown in Table 3. In the transition regime with $T_{\text {aim }}=60^{\circ} \mathrm{C}$ and $65^{\circ} \mathrm{C}$, about $40 \%$ of the lesions become visible and are visibly less pronounced than the lesions created with $T_{\text {aim }}=70^{\circ} \mathrm{C}$ and $75^{\circ} \mathrm{C}$, which are visible in $>95 \%$ of the cases.

The mean value for the end temperature $T_{\text {treatment }}$ for the irradiations with $T_{\text {aim }}=50^{\circ} \mathrm{C}, 57^{\circ} \mathrm{C}$, and $65^{\circ} \mathrm{C}$ is very close to the desired aim temperature, but the standard deviation increases.

For all temperatures, the corresponding treatment laser powers $P_{\text {treatment }}$ show a larger standard deviation (about twice the relative deviation) than the temperatures, so the site-individual temperature feedback is crucial for a reliable dosimetry.

The subvisible irradiations achieved the highest temperature accuracy regarding the absolute temperature values. Looking at the temperature distribution of the different power-controlled lesions as shown in Fig. 7, the subvisible irradiations showed the least deviation in achieved temperature with a standard deviation of $2.1^{\circ} \mathrm{C}\left(T_{\text {aim }}=50^{\circ} \mathrm{C}\right)$ and $3.8^{\circ} \mathrm{C}\left(T_{\text {aim }}=55^{\circ} \mathrm{C}\right)$. The standard deviation increases with the aim temperature $T_{\text {aim }}$, though it does not exceed $5^{\circ} \mathrm{C}$. The increase is probably mostly caused by the propagation of errors during the determination of the probe phase temperature $T_{\text {probe }}$. The broader the 
gap between $T_{\text {probe }}$ and $T_{\text {treatment }}$, the more an error in the determination of the temperature $T_{\text {probe }}$ is exacerbated for the treatment irradiation. Additionally, the temperature determination is most accurate close to the point of reference that is determined during the calibration phase.

One thing to consider specifically for higher temperatures already causing tissue denaturation is the increased light scattering. In this case, less probe and treatment laser light reaches the RPE. Furthermore, the tissue parameters and thus the Grüneisen-parameter [Eq. (3)] change. As a consequence, the temperature measurement loses its accuracy and deviations need to be taken into account, which become stronger the more the denaturation zone moves toward the inner retina.

\subsection{Temperature Measurement}

The time controlled dosimetry introduced by Schlott et al. ${ }^{25}$ and Koinzer et al. ${ }^{30}$ was shown to be effective in creating uniform lesions across a wide range of irradiation laser powers. However, with their approach, the irradiation time varies depending on the laser power and the degree of pigmentation from a few milliseconds to well over $500 \mathrm{~ms}$ in some cases. In rare occurrences, the temperature threshold for ophthalmoscopic visibility could not be reached at all, regardless of the irradiation time. This is due to the fundus tissue reaching a thermal equilibrium, where the outflux of the heat is equal to the heat induced by the absorption of the laser light. Irradiations that are too short lead to an inaccurate determination of the temperature due to the increased influence of noise in combination with the limited number of temperature data points. Also, there is a technical limitation to the response time of the algorithm at about $4 \mathrm{~ms}$. On the other hand, if the irradiation time is too long, the temperature measurement is more likely to be subject to errors due to eye movement. The variation of the irradiation time would make this approach unsuitable for automated pattern photocoagulation, where the individual irradiation has to be completed within 10 to $50 \mathrm{~ms}$. Also it was shown that while the lesions are of the same diameter, they can differ in appearance for different irradiation times. ${ }^{30}$

With the demonstrated approach here, there was no instance of not being able to reach the aim temperature up to $75^{\circ} \mathrm{C}$, improving the reliability of the dosimetry when compared to the time-variable approach. Additionally, as the treatment time is fixed at $50 \mathrm{~ms}$, the appearance of the lesions is less prone to variations. The reliable time frame also makes the powercontrolled dosimetry approach suitable to combine with some of the pattern coagulator systems operating in this time regime. The efficacy for shorter durations would have to be examined for application in pattern coagulators that operate in the $20-\mathrm{ms}$ regime.

We have found that the most critical phase during the irradiation is the probe phase, where only a slight increase in temperature is desired. It is imperative that the temperature rise above the start temperature is high enough to be fitted reliably. Several steps were taken to increase the accuracy of the temperature determination of the probe phase.

The transducer signal carries not only the pressure data, but also noise and disturbances influence the pressure value determination. It is, therefore, important to match the transducer properties to the expected signal. In order to minimize the effect, the transient curves are filtered using a bandpass filter. Based on simulations realizing the photoacoustic signal generation for an irradiation with a diameter of $200 \mu \mathrm{m}$ and a pulse duration of
$75 \mathrm{~ns}$, we expect a central frequency of the transient pressure wave of $1.2 \mathrm{MHz}$. The transducers used in this work, therefore, have a resonance frequency at $f=1 \mathrm{MHz}$ with a bandwidth of $410 \mathrm{kHZ}$. According to these considerations, the bandpass filter's upper and lower bounds were chosen to be $400 \mathrm{kHz}$ and $1.5 \mathrm{MHz}$, respectively.

Additionally, one has to consider the irradiation time. We found that $20 \mathrm{~ms}$ is a suitable irradiation time for $t_{\text {probe. This }}$ results in 20 data points to fit the temperature curves, which proved to be sufficient to achieve a reliable temperature assessment in order to calculate the power needed for the treatment phase $P_{\text {treatment }}$. However, probe repetition rate can be increased for higher accuracy.

The presented results are derived using a model for the rabbit fundus. When adapting the technique for the human fundus, some changes to the model are necessary. The different structure of the rabbit and the human eyes requires some alteration of the layer structure used for the determination of the conversion function. Additionally, the holangiotic nature of the retina requires the consideration of the absorption of laser light in the inner retina.

\subsection{Visibility Threshold}

The first visible lesions appear at a temperature of about $55^{\circ} \mathrm{C}$, albeit very rarely. For our treatment time of $20 \mathrm{~ms}$, the ED50 temperature value of creating a lesion is at $65.3^{\circ} \mathrm{C}$. This is in good accordance with results published earlier, ${ }^{25}$ where an ED50 value of $61.7^{\circ} \mathrm{C}$ for $20 \mathrm{~ms}$ can be extrapolated. However, there is no data for irradiation times of $20 \mathrm{~ms}$ to directly compare it to, as the previous experiments usually had longer irradiation times. Additionally, the fit curve derived by Schlott et al. seems to underestimate the temperatures for lower irradiation times, indicating that the ED50 value for this particular irradiation time agrees very well with the data presented here. Denton et al. have determined the threshold temperature for RPE damage as $53^{\circ} \mathrm{C}$ in the time range of $100 \mathrm{~ms}$ to $1 \mathrm{~s}$, which is considerably lower than the ED50 value found here. However, their experiments were performed on RPE cell culture and with longer irradiation times. ${ }^{37}$ According to the Arrhenius theory, one would expect the threshold temperature for shorter irradiation times to be higher than for longer ones. Additionally, the threshold for RPE damage is lower than for ophthalmoscopically visible effects, because the heat has to be conducted into to retinal layers in order to denature the tissue.

The comparison between Tables 3 and 4 shows that the fraction of visible lesions in a temperature regime is very similar to the fraction of visible lesions for a given aim temperature. This shows that the desired coagulation effect is achieved by the method.

The ED50 value found here also compares quite well with the damage threshold temperature of $63^{\circ} \mathrm{C}$ found by Sramek et al. ${ }^{11}$ for the peak temperature for 20 -ms irradiations in rabbits. Those temperatures were not measured directly, but inferred via a mathematical model based on the Arrhenius damage model.

When looking at the visibility of the lesions in Fig. 10, there is an overlap in visible and invisible irradiations between $60^{\circ} \mathrm{C}$ and $70^{\circ} \mathrm{C}$. The reason for this might be uncertainties in the determination of the temperature. The conversion function to determine the peak temperature from the measured mean temperature assumes the ratio of the absorption coefficients of the RPE and the choroid $\mu_{\mathrm{RPE}} / \mu_{\text {chor }}$ to be fixed. However, it was shown that the conversion function, and therefore, the laser-induced peak 
temperature can vary up to $9 \%$ if the ratio of absorption coefficient changes by a factor of two. ${ }^{38}$ Also there are different tissue effects, for example, the creation of edema, which lead to a whitening of the fundus area, which cannot be distinguished from thermal denaturation on the fundus image. Thus, ophthalmoscopic visibility after $1 \mathrm{~h}$ might not be the best criterion to judge the treatment outcome. We are currently investigating the visibility thresholds of alternate modalities, such as fluorescein angiography and OCT, based on a classification system published by Koinzer et al. ${ }^{39}$ Finally, it is also conceivable that there is a variance of the biological reaction to identical heat stimuli caused, for example, by a locally varying blood vessel distribution in the choroid.

\section{Conclusion}

It was shown that it is possible to reproducibly apply irradiations with subvisible and visible effects within the total time frame of $50 \mathrm{~ms}$ by automatic adjustment of the laser power once during the course of each irradiation. The precision was $3.5^{\circ} \mathrm{C}(21.2 \%)$ in the subvisible regime. An irradiation scheme was devised, with 10 system calibration pulses per spot, followed by $20 \mathrm{~ms}$ of low laser power irradiation with a moderate temperature increase for absorption balancing, which is used to determine the therapy laser power for the last $20 \mathrm{~ms}$ in order to reach the desired final temperature increase. This method with a $1-\mathrm{kHz}$ optoacoustic temperature probing was tested on rabbits in vivo for aim temperatures ranging from $50^{\circ} \mathrm{C}$ to $75^{\circ} \mathrm{C}$. The irradiations at $50^{\circ} \mathrm{C}$ remained ophthalmoscopically subvisible after $1 \mathrm{~h}$, and the standard deviation for the achieved temperatures ranged from $2.1^{\circ} \mathrm{C}$ for an aim temperature of $50^{\circ} \mathrm{C}$ to $5^{\circ} \mathrm{C}$ for $70^{\circ} \mathrm{C}$. A comparison with the used laser powers shows that the same treatment temperatures can be achieved with a wide range of irradiation powers, indicating that irradiation-site-individual absorption levels are taken into account. The ED50 value for ophthalmoscopical visibility was found to be $65.3^{\circ} \mathrm{C}$ after $1 \mathrm{~h}$, which is well supported by the literature.

This method can be well combined with automated pattern coagulators to improve the accuracy of these approaches and also to study the effects of subvisible irradiations in more detail. The next step for the presented method will be clinical trials to test the efficacy in practice and develop it toward a tool allowing for an objective and standardized examination of subvisible treatments.

\section{Disclosures}

$\mathrm{R}$. Brinkmann is an inventor of patents related to the method of temperature measurements, which are owned by Medizinisches Laserzentrum Lübeck $\mathrm{GmbH}$. The data reported in this study were acquired and processed by coauthors unaffiliated with any commercial entity.

\section{Acknowledgments}

This work was funded by the German Federal Ministry of Education and Research (No. 13GW0043B).

\section{References}

1. Early Treatment Diabetic Retinopathy Study Group, "Early photocoagulation for diabetic retinopathy. ETDRS report no. 9," Ophthalmology 98(5), 766-785 (1991).

2. Branch Vein Occlusion Study Group, "Argon Laser scatterphotocoagulation for prevention of neovascularization and virteous hemmorrhage in branch vein occlusion. A randomized clinical trial," Arch. Ophthalmol. 104(1), 34-41 (1986).

3. Central Vein Occlusion Study Group, "Natural history and clinical management of central retinal vein occlusion," Arch. Ophthalmol. 115(4), 486-491 (1997).

4. A. M. Shah, N. M. Bressler, and L. M. Jampol, "Does laser still have a role in the management of retinal vascular and neovascular diseases?" Am. J. Ophthalmol. 152(3), 332-339.e1 (2011).

5. Early Treatment Diabetic Retinopathy Study Group, "Photocoagulation for diabetic macular edema. ETDRS report no. 1," Arch. Ophthalmol. 103(12), 1796-1806 (1985).

6. G. Meyer-Schwickerath, "Light coagulation; a method for treatment and prevention of the retinal detachment," Arch. Ophthalmol. 156(1), 2-34 (1954).

7. F. A. L'Esperance, Jr., "Argon laser photocoagulation of diabetic retinal neovascularization (a five-year appraisal)," Trans. Am. Acad. Ophthalmol. Otolaryngol. 77(1), OP6-24 (1973).

8. M. A. Mainster, "Decreasing retinal photocoagulation damage: principles and techniques," Semin. Ophthalmol. 14(4), 200-209 (1999).

9. S. Al-Hussainy, P. M. Dodson, and J. M. Gibson, "Pain response and follow-up of patients undergoing panretinal laser photocoagulation (PRP) with reduced exposure times," Eye 23(2), 491 (2008).

10. M. S. Blumenkranz et al., "Semiautomated patterned scanning laser for retinal photocoagulation," Retina 26(3), 370-376 (2006).

11. C. Sramek et al., "Dynamics of retinal photocoagulation and rupture," J. Biomed. Opt. 14(3), 034007 (2009).

12. S. Y. Schmidt and R. D. Peisch, "Melanin concentration in normal human retinal pigment epithelium. Regional variation and age-related reduction," Invest. Ophthalmol. Visual Sci. 27(7), 1063-1067 (1986).

13. W. J. Geeraets et al., "The relative absorption of thermal energy in retina and choroid," Invest. Ophthalmol. 1(3), 340-347 (1962).

14. E. A. Boettner and J. R. Wolter, "Transmission of the ocular media," Invest. Ophthalmol. Visual Sci. 1(6), 776-783 (1962).

15. A. Klettner et al., "Temperature-dependent vascular endothelial growth factor (VEGF) induction in human retinal pigment epithelium-implications for transpupillary thermotherapy in uveal melanoma," Acta Ophthalmol. 90 (Suppl. 249) (2012).

16. S. M. Routt et al., "Potentiation of metalloenediyne cytotoxicity by hyperthermia," Int. J. Hyperthermia 27, 435-444 (2011).

17. A. Odergren et al., "Vision-related function after low-dose transpupillary thermotherapy versus photodynamic therapy for neovascular age-related macular degeneration," Acta Ophthalmol. 88(4), 426-430 (2010).

18. A.-C. Söderberg et al., "Combination therapy with low-dose transpupillary thermotherapy and intravitreal ranibizumab for neovascular agerelated macular degeneration: a 24-month prospective randomised clinical study," Br. J. Ophthalmol. 96(5), 714-718 (2012).

19. H. Iwami et al., "Protective effect of a laser-induced sub-lethal temperature rise on RPE cells from oxidative stress," Exp. Eye Res. 124, 37-47 (2014).

20. V.-P. Gabel, R. Birngruber, and B. Lorenz, "Clinical relevance of a dosage device for laser photocoagulation," Klin. Monatsbl. Augenheilkd. 188(4), 263-265 (1986).

21. J. K. Luttrull and G. Dorin, "Subthreshold diode micropulse laser photocoagulation (SDM) as invisible retinal phototherapy for diabetic macular edema: a review," Curr. Diabetes Rev. 8(4), 274-284 (2012).

22. D. Lavinsky et al., "Subvisible retinal laser therapy: titration algorithm and tissue response," Retina 34(1), 87-97 (2014).

23. D. Lavinsky and D. Palanker, "Nondamaging photothermal therapy for the retina," Retina 35(2), 213-222 (2015).

24. V. Chong et al., "Evolving retinal laser phototherapy: less damage is better," in Tissue-sparing Micropulse Diode Laser Photocoagulation in Practice, Supplement to Retina Today, pp. 3-16 (2011).

25. K. Schlott et al., "Automatic temperature controlled retinal photocoagulation,” J. Biomed. Opt. 17(6), 061223 (2012).

26. J. Kandulla et al., "Noninvasive optoacoustic online retinal temperature determination during continuous-wave laser irradiation," J. Biomed. Opt. 11(4), 041111 (2006).

27. G. Schule et al., "Noninvasive optoacoustic temperature determination at the fundus of the eye during laser irradiation," J. Biomed. Opt. 9(1), 173-179 (2004)

28. R. Brinkmann et al., "Real-time temperature determination during retinal photocoagulation on patients," J. Biomed. Opt. 17(6), 061219 (2012). 
29. S. Koinzer et al., "Comprehensive detection, grading, and growth behavior evaluation of subthreshold and low intensity photocoagulation lesions by optical coherence tomographic and infrared image analysis," Biomed Res. Int. 2014, 1-10 (2014).

30. S. Koinzer et al., "Temperature-controlled retinal photocoagulation-a step toward automated laser treatment," Invest. Ophthalmol. Visual Sci. 53(7), 3605-3614 (2012).

31. K. Schlott et al., "Lesion strength control by automatic temperature guided retinal photocoagulation," J. Biomed. Opt. 21(9), 098001 (2016).

32. S. Koinzer et al., "Temperature-controlled retinal photocoagulation reliably generates uniform subvisible, mild, or moderate lesions," Transl. Vis. Sci. Technol. 4(5), 9 (2015).

33. M. W. Sigrist, "Laser generation of acoustic waves in liquids and gases," J. Appl. Phys. 60(7), R83 (1986).

34. R. Birngruber, F. Hillenkamp, and V.-P. Gabel, "Theoretical investigations of laser thermal retinal injury," Health Phys. 48(6), 781-796 (1985).

35. M. Hammer et al., "Optical properties of ocular fundus tissues-an in vitro study using the double-integrating-sphere technique and inverse Monte Carlo simulation," Phys. Med. Biol. 40(6), 963-978 (1995).

36. R. Birngruber, "Thermal modeling in biological tissue," in Lasers in Biology and Medicine, F. Hillenkamp, R. Pratesi, and C. A. Sacchi, Eds., pp. 77-97, Plenum Publishing Co., New York (1980).

37. M. L. Denton et al., "Spatially correlated microthermography maps threshold temperature in laser-induced damage," J. Biomed. Opt. 16(3), 036003 (2011).

38. A. Baade et al., "Consolidated numerical temperature/pressure modelling to assess the accuracy of optoacoustic temperature determination during retinal photocoagulation," Proc. SPIE 8941, $89410 \mathrm{H}$ (2014).

39. S. Koinzer et al., "Correlation of temperature rise and optical coherence tomography characteristics in patient retinal photocoagulation," J. Biophotonics 5(11-12), 889-902 (2012).

Alexander Baade studied physics at Johannes Gutenberg University in Mainz, Germany, with an emphasis on quantum optics and computer physics. He joined the Medical Laser Center Lübeck in 2009 with a research focus on optoacoustic temperature measurements during ophthalmologic procedures. He is currently working for the FARO Scanner Production $\mathrm{GmbH}$ in Stuttgart.

Claus von der Burchard studied medicine in Kiel and Göttingen and graduated in 2014. Since then, he has worked as a resident and research fellow at the Department of Ophthalmology, University of Kiel. His research focusses on retinal diagnostics and subthreshold laser treatment of retinal disorders.

Meike Lawin studied optronics majoring photonics at the Technical University of IImenau, Germany, and graduated in 2014. Afterwards she has been researching in the field of optoacoustics at the Medical Laser Center of Lübeck until 2016. She is currently working in the field of medical engineering at the CeramOptec $\mathrm{GmbH}$ in Bonn.
Stefan Koinzer graduated with an MD degree from the University of Kiel, Germany, in 2004. He did his internship in Offenburg and Kiel and completed his specialty training in ophthalmology in 2009. Since then he has been working as a research fellow for the Department of Ophthalmology at the University of Kiel. His research has focused on RPE, retinal laser photocoagulation and ocular histopathology. He works now in private practice.

Benedikt Schmarbeck is an engineer at the Medical Laser Center in Lübeck. He has held a BSc degree in medical engineering science from the Universität zu Lübeck since 2013. In 2015, he received his MSc degree in medical engineering science from the Universität zu Lübeck. His current fields of work are biomedical imaging, interferometry, photoacoustic measurement techniques, retinal photocoagulation, and tissue optics.

Kerstin Schlott studied experimental physics at the University of Hamburg, Germany, and graduated in 2007. Since then she has been working on optoacoustic temperature measurement and automatically controlled retinal laser coagulation at the Institute of Biomedical Optics in Lübeck. Since 2014 she has been researching optoacoustic detection of laser-induced microbubbles in the pigment epithelium at the Medical Laser Center Lübeck.

Yoko Miura studied medicine in Osaka, Japan, and received a medical license in 1997 and her PhD in 2002. After working as an assistant professor in the Department of Ophthalmology at Osaka City University till 2006, she undertook basic research at the university eye clinic in Kiel. In 2009, she moved to Lübeck, received a German medical license in 2012, and today is a faculty member at the Institute of Biomedical Optics, University of Luebeck.

Johann Roider, MD, is a professor of ophthalmology. He studied mathematics, physics, and medicine at Munich universities, Germany. He did a research fellowship at the Wellman Laboratories of Photomedicine, Boston. His clinical training was obtained at the universities of Lübeck and Regensburg. Since 2002 he has been the chairman of the Department of Ophthalmology, University of Kiel. His research focuses are laser-tissue interactions and vitreoretinal disorders.

Reginald Birngruber studied electrical engineering and physics and graduated in physics (PhD) and in medical biophysics (MD habilis) in Germany. After his retirement from CEO and CRO of the Medical Laser Center Lübeck and the chair of the Institute of Biomedical Optics, he now makes his expertise and contacts available to colleagues in Lübeck and Boston. Current activities include mechanisms of laser tissue effects, optical tissue diagnostics, laser therapy control and new therapeutic techniques.

Ralf Brinkmann studied physics at the University of Hannover, Germany, with a focus on quantum optics and lasers. After a 5-year industrial interim period, he joined the Medical Laser Center in Lübeck, Germany, in 1993, and received his PhD from the University of Lübeck. Since 2005 he has been holding a permanent position as a faculty member at the University Institute of Biomedical Optics, and is also leading the Medical Laser Center as CEO. 